Fecha de recepción: diciembre 2017 Fecha de aceptación: marzo 2018 Versión final: julio 2019

\section{On Digital Citizenship and Data as a New Commons: Can We Design a New Movement?}

Ingrid Mulder ${ }^{\star}$, Tomasz Jaskiewicz ${ }^{\star *}$ and

Nicola Morelli ${ }^{\star * \star}$

\begin{abstract}
Along with the urgent need to reinvent our society, a series of paradigm shifts are already shaping transitions toward a more participatory and digital society. The current work takes stock of the promise of open data as a new resource and elaborates upon the maker movement, which has spurred people's capacity to participate and has provided tools and infrastructures to unleash people's intrinsic ability to create and innovate. We explore how open data can be a new commons, discuss how hackathons can support digital citizenship, and reflect on the role of Transition Design in creating ecosystems around the common resource and in building capacity.
\end{abstract}

Key words: capacity building - data literacy - diffuse design - digital citizenship - hackathons - open data - paradigm shift - societal challenges - Transition Design.

[Abstracts in spanish and portuguese at pages 108-109]

${ }^{(*)}$ Ingrid Mulder is an Associate Professor of design techniques, Faculty of Industrial Design Engineering, Delft University of Technology. Her expertise is in design for social transformations. With a background in Policy and Organization Sciences (MA, University of Tilburg) and Behavioral Sciences (PhD, University of Twente), her ongoing teaching and research activities combine strategic design with diffuse design while addressing the interplay between top-down policy and bottom-up participatory innovation. I.J.Mulder@tudelft.nl

${ }^{(*)}$ Tomasz Jaskiewicz is an Assistant Professor of interactive design prototyping at the Faculty of Industrial Design Engineering, Delft University of Technology. He holds master degrees in Architecture and Urban Design (MSc, TU Gdansk, Poland; MSc and PhD, Faculty of Architecture and Built Environment, Delft University of Technology). His teaching and research activities focus on tools and methods for designing large-scale interactive systems and installations. T.J.Jaskiewicz@tudelft.nl

${ }^{(* *)}$ Nicola Morelli is Professor with Special Responsibilities at Aalborg University, Denmark. He holds a PhD in Industrial Design at Politecnico di Milano. He is teaching and collaborating in the Masters in Service Systems Design program at Aalborg University in Copenhagen. Nicola is the project coordinator of the Open4Citizens project. He also works on other EU funded research projects, namely DesignScapes and MUV. His research focus is on service design strategies and methodologies and on the role of design in supporting social innovation.nmor@create.aau.dk 
"The world is undergoing immense changes. Never before have the conditions of life changed so swiftly and enormously as they have changed for mankind in the last fifty years" (Loorbach, 2014). Our society is increasingly digitalized and transforming into a participatory, collaborative, and circular economy. Botsman (2013) points out that two, or even three, major paradigm shifts are shaping the transition towards a collective society. A society that is shifting from a hierarchical to a network-based structure, on the one hand, is combined with a shift from scarcity to a surplus of underutilized assets, on the other hand. A third shift, still looming on the horizon, is addressing the alternative currencies and rating and curating methods that are needed to answer the diverse needs and values of the open cities of tomorrow. Although, one might argue that the participatory turn has been enabled through top-down voices, such as the promise of smart cities, the participation society, and the corresponding decentralization of the social domain, the collaborative society is being shaped through bottom-up participatory innovation paradigms, in the first place, designated by community groups reclaiming the public domain and who are increasingly willing to take greater control. These bottom-up trends have spurred a demand for new forms of self-organizing governance. In this turn to a collective or sharing economy, networks of individuals act as platforms. The collaborative phenomenon is much more than a trend or a hype -it is a movement, affecting society at large. It can also be seen as a series of paradigm shifts empowering and enabling society to transition. Today's societal challenges are increasingly putting pressure on the need to change (MaxNeef, 1991). Transition Design, as introduced by Irwin, Kossoff, and Tonkinwise (2015), explicitly acknowledges that we are living in transitional times and takes the need for societal transitions to more sustainable futures as its central premise, arguing that design has a key role to play in these transitions. Additionally, Mulder and Loorbach (in press) highlighted the importance of framing transitions as collective societal design challenges. Hence, we can no longer rely on optimizing existing systems, infrastructures, technologies, or knowledge infrastructures to deliver the necessary transitions. Transition Design as an emerging design discipline can play a critical part in moving away from unsustainable, locked-in regimes through processes of societal experimentation, iteration, prototyping, and scaling, guided by inspiring visions and future images. However, how this changing profession of designers should be shaped in order to be of value in societal transitions is not straightforward.

The current work aims to contribute to this debate and starts exploring how Transition Design can play a role in further diffusing both design and digital skills in society in order to broaden society's capacity to change. We take stock of the potential of open data as a new resource and leverage on the benefits of the digital transformation and the maker movement that has spurred people's capacity to participate and make. Next, we introduce our approach and the corresponding tools and infrastructures aiming to empower people in making meaningful use of these data. We conclude with a discussion and reflect on the role of Transition Design in establishing a new social infrastructure and building capacity. Can we catalyze a movement? 


\section{The Promise of Open Data}

Recent years have seen the introduction of legislation on multiple levels of government that should enable the release of public sector information without reuse restrictions, that is, as open data. In the United States, President Obama has been in favor of data release (Obama, 2009). In particular, the Memorandum on Transparency and Open Government, signed in January 2009, declared his administration's commitment to creating an unprecedented level of openness in government and establishing a system linking three principles: transparency, participation, and collaboration. In the EU, a similar position was taken by the European Commissioner for Digital Agenda, Neelie Kroes (Kroes, 2011). The 2003 Public Sector Information (PSI) Directive of the European Parliament and the European Council also supports the release of PSI (European Commission, 2003). Ever since, public administrations around the world have embarked on open government initiatives and have worked to redefine their relationship with citizens and with each other. The benefits attributed to open government are manifold. They include claims that open government leads to more effective decision-making and services, safeguards against corruption, enables public scrutiny, and promotes citizens' trust in government, including better achievements of effectiveness, efficiency, or accountability. Public sector information when released into the public domain is deemed suitable for reuse by citizens and made available for the creative industry to build on and create new services.

Open data is generally seen as a promising concept to boost the co-production of new public services. Policy makers and politicians stress the potential benefits to transparency and innovation as a result of data release, in addition to better decision-making (Bertot, Jaeger, \& Grimes, 2010; Kroes, 2011; Obama, 2009). Illustrating the potential financial benefits of publishing data is the MEPSIR study, wherein the value of the PSI market is estimated at $€ 27$ billion (Dekkers, Polman, te Velde, \& de Vries, 2006). National governments have been providing instructions to make an effort to provide PSI to the larger public, and local governments need to define their own open data policies and create internal processes to do so. While there is consensus on the value of PSI for innovation and transparency, the exact impacts and benefits of open data policies still remain unclear.

\section{Open Data as a Resource}

In its premise, open data can contribute to transparency, aiming to improve the decisionmaking process in general. However, how these open data contribute to citizen participation and an inclusive society is less straightforward. This increased call for data release by governmental agencies is oftentimes a result of national policies or may be a call from active citizens, which is frequently presented in a provocative tone. Citizen's rights to the digital city seems to go hand in hand with citizens' distrust in government and/ or wish to take over governmental control. At the same time, citizens do not have equal access to these open data, even when the data is available, as it is hard to articulate the right questions needed to obtain the data; furthermore, demand for open datasets publication is probably hindered by the consolidation of publication formats and adequate aggregation of datasets. In our current work, we aim to support citizens in their right to initiate social 
change and (the right) to challenge governments through addressing systemic barriers that cause inequity. The premise is that open data represents a new resource that is available to all, not just to data owners or large companies, but also to citizens, public administrators, and interest groups.

\title{
Open For Citizens
}

The Horizon2020 CAPS project Open4Citizens explores how open data can be considered as a new commons, and it supports citizens through hackathons in making meaningful use of these data. More precisely, the Open4Citizens project aims to broaden citizens' skillset towards meaningful use of open data (Morelli et al., 2017). The corresponding OpenDataLabs established in five pilot cities -Barcelona, Copenhagen, Karlstad, Milan, and Rotterdam- will help to overcome the cognitive gap the majority of citizens may have with respect to open data by making knowledge available. In these labs, citizens will experience the practical value of open data in the conception, modification, adaptation, and maintenance of urban services and explore hackathons as new forms of collaboration by explicitly connecting bottom-up initiatives and top-down policies through dialogue and co-creation.

As open data are seen as a new commons, the Open4Citizens' OpenDataLab clearly distinguishes itself from similar initiatives such as coding hackathons or service jams. OpenDataLab's focus is on empowering citizens to make meaningful use of open data and to support existing citizen initiatives. Open data can become a common resource if communities are built around them and create sets of practices and rules to use this resource in the most sustainable way.

\begin{abstract}
Approach
The particular Open4Citizens approach aims to (a) aggregate a community that takes care of and uses the resource, (b) develop a set of practices for using the resource, and (c) provide infrastructure to the community through a set of tools that facilitate access to the resource and its usage (see Morelli et al., in press). Morelli and colleagues (in press) elaborate on the creation of the needed infrastructure for the exploitation of open data as a new commons, as well as on the aggregation of communities (ecosystems) of users, highlighting the hackathon process as an instrumental means to facilitate the creation of this culture. The $\mathrm{O} 4 \mathrm{C}$ approach, through the various components indicated above, is structured upon the extension of the hackathon from a two- or three-day pressure cooker coding event to a process of five to six months, including a preliminary phase (pre-hack) in which the community and the resources (datasets) are aggregated, a hackathon event, and a posthack phase in which the hackathon's outcomes are developed and tested. The process of "infrastructuring" goes along all those phases: engaging citizens in the pre-hack, providing tools for co-creation ( $\mathrm{O} 4 \mathrm{C}$ toolkit, data tool), and infrastructure (the $\mathrm{O} 4 \mathrm{C}$ platform) in the hackathon phase and providing infrastructure for incubation (the OpenDataLab) in the post-hack phases (See Figure 1).
\end{abstract}



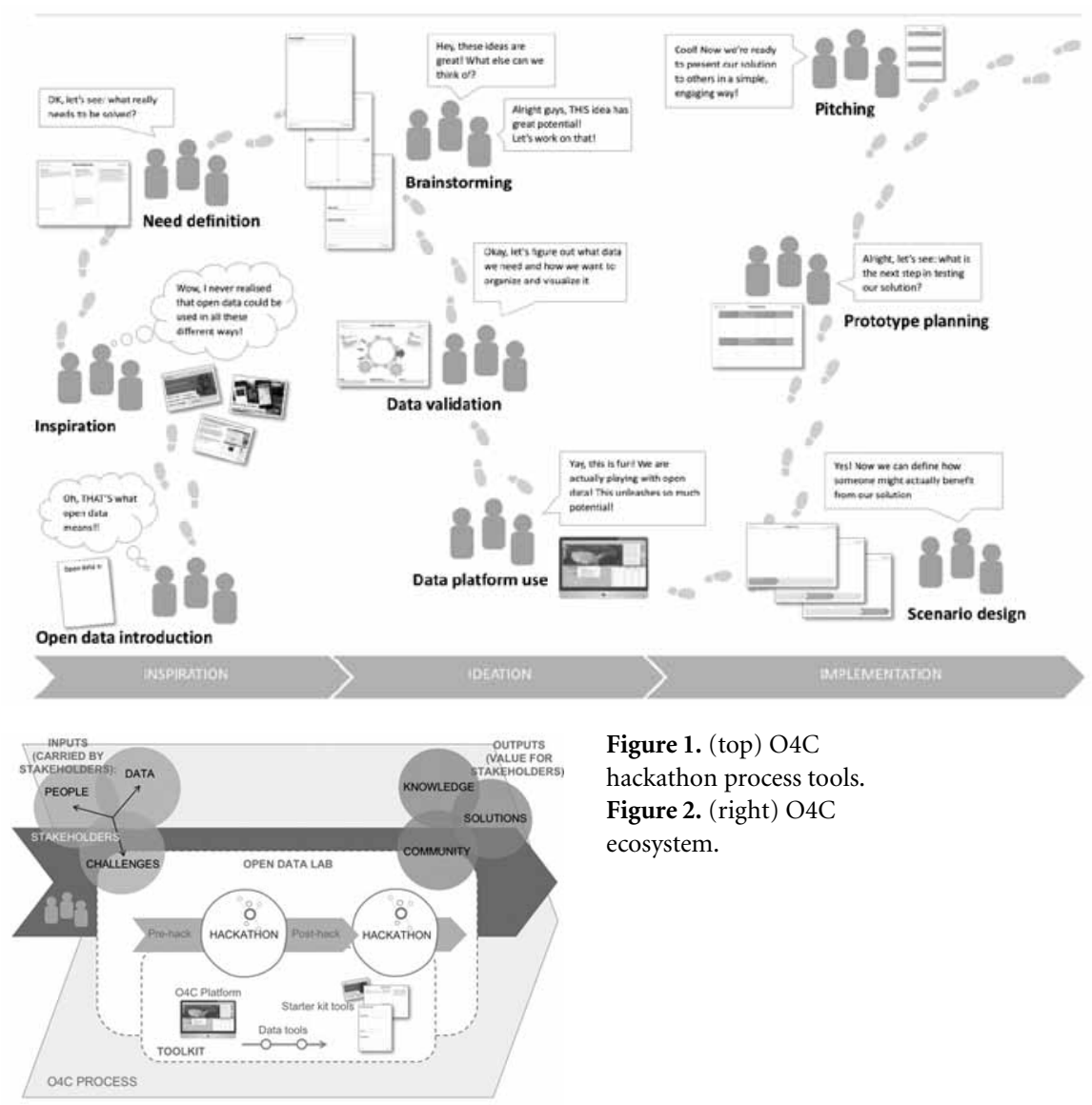

Figure 1. (top) O4C

hackathon process tools.

Figure 2. (right) $\mathrm{O} 4 \mathrm{C}$

ecosystem.

The OpenDataLabs, hackathons, and $\mathrm{O} 4 \mathrm{C}$ toolkit are the three main concepts that structure the work of the $\mathrm{O} 4 \mathrm{C}$ project, as indicated in the $\mathrm{O} 4 \mathrm{C}$ ecosystem (See Figure 2). The OpenDataLab is a physical and virtual infrastructure that supports a broader use of open data among citizens, interest groups, and public institutions; it is also a network structure that links the OpenDataLabs in different locations to cross-pollinate knowledge about the use of open data across different communities. It defines hackathons as a set of practices that actively support citizens' initiatives and the creation of events that involve participants with different knowledge and competences. Finally, it provides an overview of the toolkit that supports the actual co-creation process through a "hackathon starter kit", data tools, and the $\mathrm{O} 4 \mathrm{C}$ platform. 


\section{Hackathons for Construction of Common Practices to Work with Open Data}

Open data can only become a new commons if a community and a set of practices is created around it. Therefore, community building is part of the creation of the OpenDataLab ecosystem, whereas the set of practices is structured around the $\mathrm{O} 4 \mathrm{C}$ hackathon process. The $\mathrm{O} 4 \mathrm{C}$ hackathon process provides a workflow that coordinates tools, processes, and knowledge for developing new and innovative public services, based on open data, with the active contribution of non-IT savvy citizens and the support of experts. The direct involvement of citizens will make the hackathon results much more likely to be taken up and will facilitate the integration and scaling up of the new services. One of the challenges faced by the consortium is developing approaches for attracting citizens and other stakeholders to be involved in these hackathons.

Besides sharing the same tools, methods, expertise, and knowledge, all OpenDataLabs adopt the three-stage hackathon "funnel" workflow. As Figure 3 shows, an initial pre-hack phase is characterized by intense activity focused on dataset identification, verification, and specification, running in parallel with the process of defining the challenge(s) that the hackathon is meant to address. Ideally, the emergent need for specific datasets that are not yet in the public domain, which would enable the proper functioning or performance of the applications under development, should prompt data owners to promote faster, more effective policies and practices of public sector information disclosure. Alongside the delivery of open data-driven solutions, additional benefits can be identified in the reinforcement of citizen interest and in the diffusion of domain-related and thematic knowledge among the participants and external observers, who are the most likely actors to step into a subsequent edition of the hackathon itself.

The above expresses the essence of the OpenDataLab innovation potential at both the local community level -as an enabler of public service co-creation by non-IT-savvy citizensand at the global network level -as the common and joint output of initiatives and collaborations by all the nodes of the OpenDataLab network. More specifically the output of every innovation process in the OpenDataLab is expected to generate not only specific solutions but also more knowledge about open data practices and opportunities (See Figure 3).

Building the capacity of OpenDataLabs participants is connatural to all planned activities. Targets of this effort include people working inside them and those attracted by their initiatives. For instance, offering access to Open Data has a training or capacity building component, as does public service co-creation via O4C hackathons, using service design tools, methodologies, and processes, and the support the project is meant to provide to hackathon facilitators. Finally, education about digital citizenship is the ultimate longterm goal of an OpenDataLab.

\section{OpenDataLab Rotterdam}

The municipality of Rotterdam has embraced the 'right to challenge' as part of their transformed governance structure aiming to enhance active societal participation. The right to challenge is a shared initiative of Dutch local municipalities aimed at encouraging citizens to challenge their municipalities. This initiative initially focused on topics related to citizen health and well-being, but it is currently being extended to a multitude 


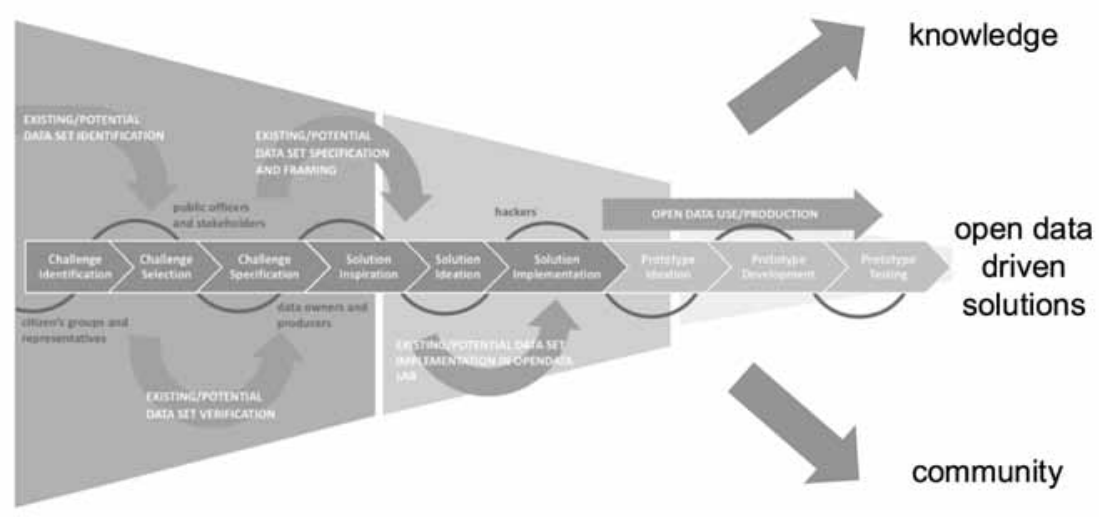

Figure 3. The three-stage hackathon "funnel".

of domains of interest where citizen activism takes place. In keeping with the spirit of the right to challenge, OpenDataLab Rotterdam focuses on the self-management of public parks. Self-management of public parks is a theme instantiating the transformation towards participatory city governance and involvement of active citizenship in city planning and organization. The sphere of a public park offers an opportunity to embrace multiple aspects of potential citizen engagement, as even one single park permits the coexistence of heterogeneous types of shared citizen initiatives. This provides an opportunity to study, compare, and stimulate a variety of citizen initiatives within one case study theme.

Specific topics related to public parks include provision of space for shared social activities (such as gardening, social meetings, events, and leisure activities), health-related initiatives (such as improvement of air quality, sports, and healthy lifestyle and outdoor activities), cultural and cross-cultural initiatives (such as festivals and cultural integration), heritage initiatives (such as promoting and spreading awareness of the history of the city), and stimulating engagement of citizens in city developments (such as area redevelopment plans). The overlap of these topics and the introduction of new topics emerging from citizens' needs provide additional opportunities for innovative solutions. Questions already expressed by parties involved in this project relate to better articulation of the social and financial value of social engagement initiatives around public parks in order to be able to challenge the public administration. What are the costs of green maintenance of a park? How do you allocate the available resources as efficiently as possible? Which business models are available? But also, how can more volunteers be involved in the park initiatives? How can communications be improved and become self-sustaining?

The primary focus of OpenDatalab Rotterdam is raising awareness of data and increasing participants' data literacy to facilitate wider support for innovative ideas and joint implementation. In other words, OpenDataLab Rotterdam does not "hack" the existing system, 
but it explicitly facilitates joint exploration, learning from each other, and contributing to a viable and resilient city. For example, the municipality is explicitly exploring ways to include the collaborative learning process and the outcomes of the Park Hackathon in the program Democratic Challenge, a process that started with residents and other stakeholders in Delfshaven exploring the co-creation of new forms of direct democracy (decision-making rather than representative) by residents on issues -such as the establishment of a common courtyard- that are important to residents in daily practice and in their own neighborhood.

\section{OpenDataLab Copenhagen}

The O4C pilot in Copenhagen organized its first hackathon in October 2016 and is now in the process of organizing a second hackathon to take place in November 2017. The first hackathon focused on migration and integration. During the organization of the first hackathon cycle, the migration theme was in the center of public discussion in Denmark, in part because of some controversial decisions of the Danish government regarding rules for accepting new migrants. In addition to the operative aspects implied by those decisions, the debate centered on how to integrate the newcomers into Denmark and how to support them with adequate services. The $\mathrm{O} 4 \mathrm{C}$ team assumed that this would attract the attention of citizens, public institutions, interest groups, and even private companies. The pre-hack phase revealed that, although the interest in this topic is very high, the ecosystem around this issue is not yet consolidated: there were not enough datasets available and few of them were publicly available. Furthermore, the public authorities who were contacted were reluctant to participate in the hackathon because the responsibility for managing various aspects of immigration and integration was not very well defined or well distributed among different public institutions. However, the hackathon attracted the interest of citizens, students, and some private organizations that were already working on the integration of newcomers into the Danish economy. The results of the first hackathon were heavily influenced by the flaws in the initial hypotheses: the lack of data did not give the participants the opportunity to generate a real service prototype, as expected; instead, more generic concepts were proposed, some of which were further developed into solutions that were not based on open data. Moreover, the lack of commitment from public authorities precluded any possibility of obtaining relevant data and developing or integrating the concepts resulting from the hackathons into new or existing public services. Rather than a failure, the results confirmed the need for a solid pre-hack process, based on three pillars: (a) a valid and relevant challenge, (b) the availability of a consistent number of datasets, and (c) the participation of relevant stakeholders. The first pilot in Copenhagen was based on the definition of the challenge, as described in Figure 3, but neglected the research and validation of datasets and was unable to consolidate the participation of relevant social groups.

The second hackathon cycle is learning from this lesson and is shifting the direction of the challenge to address these neglected factors. The new hackathon will focus on outdoor tourism in the northern region of Denmark. Although less present in public debate, this is a challenge on which several institutions are now working, from public institutions (several municipal administrations in the region and the regional authority that promotes local 
business) to private organizations (tourist operators in Nord Jutland) and research institutions. Many of these groups already own or are aware of potential datasets that can be used in the hackathon. The ecosystem being organized includes data owners (public authorities and associations of municipalities), problem owners (tourist associations), and other relevant actors, such as municipalities, citizen organizations, and potential coders. A second lesson learned from the first cycle concerns the definition of the problem. The first hackathon event started with the early phases of the hackathon kit described in Figure 1 , that is, inspiring the participants about the potential of open data. This limited the time spent on the development of valid concepts. On this ground, and also from the observations of other pilot program teams, the Copenhagen team decided to start the co-creation process in the pre-hack phase. This not only creates the conditions to specify the challenges at the very beginning of the hackathon but it also activates the stakeholders' ability to identify useful datasets for use in the hackathon.

Although the hackathon event has not yet started as of this writing, the process has already identified and specified five themes for the challenges and a number of datasets that are directly or indirectly related to each of the challenges. This is a promising element that may increase the possibility of obtaining interesting and operational outcomes from the hackathon.

\section{Discussion and Conclusions}

The experiences described in the previous cases suggest that the hackathon is a useful learning tool for citizens and communities. Furthermore, the hackathon can be a tool for capacity building and can become a practice that transforms open data from a public resource to a commons (Morelli et al., 2017). However, the present conceptualization of the hackathon event needs to be revised. An O4C hackathon is a learning tool, in which the capacity building activity is developed through the pre-hack process by aggregating an ecosystem of relevant actors and by working together to build competencies and knowledge about the available open datasets and opportunities to use them. While the hackathon itself is an activity that triggers citizens' creativity, supports social interaction, and generates opportunities for conversation among citizens, the construction of the ecosystem for the hackathon is an activity that aims at shaping the contextual conditions (political, administrative, business related) that are intended to incubate and support the hackathon results. The hackathon itself can be seen as an infrastructure that supports both the interaction among citizens and the construction of systemic conditions around the initiatives. The hackathons not only create civic engagement and data awareness and support digital citizens' pedagogy but they also link new forms of participation that propose new approaches to city-making or large systemic changes.

\section{Infrastructuring Digital Citizenship}

It can be concluded that the lessons learned across the pilot cities demonstrate an increased awareness among hackathon participants of the opportunities offered by open 
data; a broader diffusion of creative (design thinking) capabilities within hackathon participants; cultivation of technical skills among the hackathon participants, to help them ideate and co-create new applications based on the datasets (that could be) made available by their owners; and dissemination of obtained knowledge and skills by hackathon participants to the broader OpenDataLab community and the general public.

More precisely, our lessons can be clustered along three logical levels: value in use, infrastructuring, and ecosystemic level.

Value in use is the logical level referring to the very moment in which value is created. According to Vargo and Lusch (2008), this is the moment in which users (Vargo and Lusch refer to them as beneficiaries) aggregate a set of operant resources to create value. Such resources consist of products, services, personnel, and knowledge. In the $\mathrm{O} 4 \mathrm{C}$ project, value co-production through resource aggregation happens thanks to the interactions in the hackathon.

The interaction at this level depends on the stakeholders' diffuse design capability, generated by the negotiation among different problem-solving attitudes and strategies of the participants. The designers' problem-solving capabilities are just one of the components of this negotiation. At this level, the designers' expert contribution consists of using inspiration cards, prototypes, visual representations, and other tools to support the design process. The outcomes of the collaborative design activity at this level are the design solutions generated by the heterogeneous competences involved in the project.

Infrastructuring is the activity of expert designers that consists of generating logical structures (blueprints, templates, modular structures, and working frameworks) or physical structures (services, products, and events) that facilitate the process of value co-creation (Morelli et al).

Within the $\mathrm{O} 4 \mathrm{C}$ project, the outcomes of the design activity at this level include the organization of the hackathon cycle and the body of knowledge for a systematic application of models, tools, and IT infrastructures (the O4C online platform) that can be used in the hackathon.

Designers define ecosystems to identify technical, social, and contextual conditions, aggregating and motivating actors to make the design action scalable and reproducible in different contexts. The design action at this level may concern incremental systemic changes or even broader transitions. In the latter case, the design action aims to introduce elements that facilitate negotiations and visions of possible future configurations. In the $\mathrm{O} 4 \mathrm{C}$ project, this logical level includes the definition of the OpenDataLab, its scenarios and conditions of use, and the identification of the crucial stakeholders. The design knowledge needed at this level refers to the ability to understand the socio-technical implications of the proposed transformations into the ecosystem around the OpenDataLab. Therefore, it implies a wider, transdisciplinary, and systemic perspective of a specific problem area and the relevant ecosystem. Besides the OpenDataLab, the outcomes of the design activity at this level are frameworks for action and policies that will infrastructure digital citizenship and equality in using their rights to initiate and to challenge in the digital city. 


\section{Designing for Transitions}

The three-level framework outlined above describes the possible contribution of design to both minor and large transitions, by linking the activity of design as an active agent of change -supporting interaction, engaging and enabling citizens- to more consolidated design activities -creating products, services, and infrastructures- up to higher levels in which design is an agent of broader transitions.

How can design empower more people as change makers and accelerate transition processes? Our lessons show that a smart combination of diffuse and expert design enables infrastructuring of digital citizenship through the diffusion of creative and digital skills. The $\mathrm{O} 4 \mathrm{C}$ approach encouraged articulation of issues before starting into data analysis. The collaborative reframing of the challenges changed the focus to more critical whyquestions and encouraged participants to articulate better data requests necessary to demonstrate the societal value of their initiatives. In this way, the bottom-up hackathons showed the importance of story-finding as a scaffold for data literacy. In addition, the rich and contextually grounded insights enabled the citizen hackers to combine these "thick" data in such a way that they form a coherency that can be acted upon (Lodato \& DiSalvo, 2016). The collaborative construction of the dialogue allows for collaborative learning, and it resulted in powerful narratives that enabled participants to take the hack proposals to the next step.

Earlier work on infrastructuring demonstrated the role of design in amplifying and connecting the power of bottom-up design (Manzini \& Rizzo, 2011). Expert design interventions can be seen as small-scale experiments enabling social innovation. Although these social innovation experiments are niches within larger transitions, the ways that design can accelerate transitions are not straightforward. The current work, however, shows that the concept of data as a common (resource) strengthens "communing", as coined by Linebaugh (2009). One of the main outcomes of the hackathons was the strengthening of these networks and empowerment to make/take next steps. It can be concluded that a broader diffusion of design skills contributes to co-creating or creating ecosystems around the common resource and to the enhancement of society's (design) capacity to change.

\section{References}

Bertot, J. C., Jaeger, P. T., \& Grimes, J. M. (2010). Using ICTs to create a culture of transparency: E-government and social media as openness and anti-corruption tools for societies. Government Information Quarterly, 27(3), 264-271.

Botsman, R. (2013, November 21). The sharing economy lacks a shared definition. Retrieved from: http://www.fastcoexist.com/3022028/the-sharing-economy-lacks-a-shareddefinition\#4

Dekkers, M., Polman, F., te Velde, R., \& de Vries, M. (2006, June). Mepsir: Measuring European public sector information resources. Final report of study on exploitation of public sector information - benchmarking of EU framework conditions. Brussels: European Commission. 
European Commission (2003). Communication of the re-use of public sector information - Review of Directive 2003/98/EC. Regulation.

Irwin, T., Kossoff, G., \& Tonkinwise, C. (2015). Transition Design provocation. Design Philosophy Papers, 13(1), 3-11.

Kroes, N. (2011). Public data for all - opening up Europe's public sector: 2011. Retrieved from http://blogs.ec.europa.eu/neelie-kroes/public-datafor-all---opening-up-europespublic-sector/

Linebaugh, P. (2009). Magna Carta manifesto: Liberties and commons for all. Berkeley, CA: University of California Press.

Lodato, T. \& DiSalvo, C. (2016). Issue-oriented hackathons as material participation. New Media and Society, 18(4), 539-557.

Loorbach, D. (2014, October 31). To transition! Governance panarchy in the new transformation. Inaugural Address, Rotterdam: Erasmus University Rotterdam.

Manzini, E., \& Rizzo, F. (2011). Small projects/large changes: Participatory design as an open participated process. CoDesign, 7(3-4), 199-215.

Max-Neef, M. A. (1991). Human scale development: conception, application and further reflections. New York: The Apex Press.

Morelli, N., Aguilar, M., Concilio, G., De Götzen, A., Mulder, I., Pedersen, J., \& Torntoft, L. K. (2017). Framing design to support social innovation: The Open4Citizens Project. The Design Journal, 20(sup1), S3171-S3184. doi:10.1080/14606925.2017.1352823

Morelli, N., De Götzen, A., Mulder, I., Concilio, G., Pedersen, J., Jaskiewicz, T., \& Aguilar, M. (in press). Open data as a new common. Empowering citizens to make meaningful use of a new resource. Proceedings of INSCI 2017, the 4th International Conference on Internet Science.

Mulder, I., \& Loorbach, D. (in press). Rethinking design: A critical perspective to embrace societal challenges. Proceedings of Transition Design Symposium 2016.

Obama, B. (2009). Transparency and Open Government: The White House: 2009. Retrieved from http://www.whitehouse.gov/the_press_office/Transparency_and_Open_Government. Vargo, S. L., \& Lusch, R. F. (2008). Service-dominant logic: Continuing the evolution. Journal of the Academy of Marketing Science, 36, 1-10.

Resumen: Junto con la urgente necesidad de reinventar nuestra sociedad, una serie de cambios de paradigma ya están dando forma a las transiciones hacia una sociedad más participativa y digital. El trabajo actual hace un balance de la promesa de los datos abiertos (open data) como un nuevo recurso y elabora sobre el movimiento creador, que ha estimulado la capacidad de las personas para participar y ha proporcionado herramientas e infraestructuras para liberar la capacidad intrínseca de las personas para crear e innovar. Exploramos cómo los datos abiertos pueden ser nuevos comunes, discutimos cómo las hackatones pueden apoyar la ciudadanía digital y reflexionamos sobre el papel del Diseño para la Transición en la creación de ecosistemas en torno al recurso común y en la creación de capacidad. 
Palabras clave: Desarrollo de capacidades - alfabetización de datos - diseño difuso - ciudadanía digital - hackathons - datos abiertos (open data) - cambio de paradigma - desafíos sociales - Diseño para la Transición.

Resumo: Junto com a urgente necessidade de reinventar nossa sociedade, uma série de mudanças de paradigma já está dando forma às transições até uma sociedade mais participativa e digital. Este trabalho faz um balanço da promessa dos dados abertos (open data) como um novo recurso e fala sobre o movimento criador, que estimulou a capacidade das pessoas para participar e proporcionou ferramentas e infraestruturas para liberar a capacidade intrínseca das pessoas para criar e inovar. Exploram-se como os dados abertos podem ser novos comuns, como as hackatones podem apoiar a cidadania digital e reflete-se sobre o papel do Design para a Transição na criação de ecossistemas em torno ao recurso comum e na criação de capacidade.

Palavras chave: Desenvolvimento de capacidades - alfabetização de dados - design difuso - cidadania digital - hackathons - dados abertos (open data) - mudança de paradigma desafios sociais - Design para a Transição. 